\title{
Comparative cost-effectiveness of a fluticasone- propionate/salmeterol combination versus anticholinergics as initial maintenance therapy for chronic obstructive pulmonary disease
}

\author{
This article was published in the following Dove Press journal: \\ International Journal of COPD \\ 30 December 2010 \\ Number of times this article has been viewed
}

\author{
Anand A Dalal' \\ Melissa H Roberts ${ }^{2}$ \\ Hans V Petersen ${ }^{2}$ \\ Christopher M Blanchette ${ }^{3}$ \\ Douglas W Mapel ${ }^{4}$ \\ 'US Health Outcomes, \\ GlaxoSmithKline, Research Triangle \\ Park, NC; ${ }^{2}$ Division of Clinical \\ and Outcomes Research, Lovelace \\ Respiratory Research Institute, \\ Albuquerque, NM; ${ }^{3}$ Kannapolis, North \\ Carolina; ${ }^{4}$ Lovelace Clinic Foundation, \\ Albuquerque, NM, USA
}

Purpose: Relative costs and utilization-related outcomes of a fluticasone propionate $250 \mu \mathrm{g}+$ salmeterol $50 \mu \mathrm{g}$ combination (FSC), tiotropium bromide, and ipratropium as initial maintenance therapy in COPD have not been compared in a commercially-insured population.

Methods: This retrospective, observational cohort study used health care claims data from January 2004 to June 2009 from a large administrative database for patients aged $\geq 40$ years with COPD. Time-to-first COPD-related health care event beginning 30 days following therapy initiation with FSC $(\mathrm{n}=16,684)$, ipratropium alone or in fixed dose combination with albuterol ( $\mathrm{n}=14,449)$, or tiotropium $(\mathrm{n}=12,659)$ was estimated using Cox proportional hazard models that controlled for differences in patient demographic characteristics, health care utilization, and comorbidities at baseline. Mean adjusted costs and numbers of COPD-related health care encounters and prescription medication fills were compared among patients with 12 months of follow-up (FSC, $\mathrm{n}=12,595$; ipratropium, $\mathrm{n}=10,617$; tiotropium, $\mathrm{n}=9126$ ).

Results: With FSC as the reference, risk for a COPD-related hospitalization and/or emergency department visit was significantly higher for ipratropium (hazard ratio [HR] 1.64, 95\% confidence interval [CI] 1.50-1.79) and tiotropium (HR 1.29, CI 1.17-1.41). Mean adjusted 12-month COPD-related total health care costs were lower for FSC (\$2068, standard deviation [SD] \$1190) than for ipratropium (\$2841, SD \$1858) and tiotropium (\$2408, SD \$1511, both $P<0.05)$. Mean number of COPD-related hospitalizations, emergency department visits, and outpatient visits associated with an oral corticosteroid or antibiotic were also lower for FSC than for ipratropium and tiotropium (all $P<0.05$ ).

Conclusions: In this retrospective "real-world" observational sample of COPD patients, initiating treatment with FSC was associated with significantly better clinical and economic outcomes compared with short- and long-acting anticholinergic therapy. Consistent with the goal of preventing and reducing exacerbations advocated by global guidelines, the findings suggest that initiation of maintenance treatment with FSC may afford clinical benefits at a lower cost than anticholinergic treatment.

Keywords: chronic obstructive pulmonary disease, Advair $^{\mathbb{R}}$, tiotropium, ipratropium, utilization, costs

\section{Introduction}

The use of appropriate medications for the treatment of chronic obstructive pulmonary disease (COPD) is essential to improve patient quality of life and minimize the substantial burden of illness that COPD places on the health care system. The grow- 
ing population of individuals with COPD, comprising an estimated 24 million adults in the US, costs the nation approximately $\$ 42.6$ billion each year, including $\$ 26.7$ billion in direct costs and $\$ 15.9$ billion in indirect costs. ${ }^{1,2}$ In addition, because COPD is a systemic disease, the presence of COPD-related comorbidities increases as the disease progresses, adding significantly to the disease burden.

Maintenance therapies for COPD that are recommended in widely accepted clinical guidelines include long-acting beta-agonists (LABAs) alone, inhaled corticosteroids (ICS) alone, ICS plus LABA, and anticholinergic agents. ${ }^{3,4}$ In various COPD populations, the combination of ICS plus LABA for maintenance therapy, including the combination medication of fluticasone propionate $250 \mu \mathrm{g}+$ salmeterol $50 \mu \mathrm{g}$ (FSC), has been associated with a significantly lower risk for COPD-related hospitalizations, emergency department visits, and health care costs compared with ipratropium, a short-acting anticholinergic. ${ }^{5-11}$ Tiotropium bromide, a long-acting anticholinergic, also has been shown to reduce exacerbations and COPD-related hospitalizations compared with ipratropium. ${ }^{12,13}$

To our knowledge, no studies have directly compared both the clinical and economic outcomes of these three maintenance therapies, in particular FSC and tiotropium, in a population of commercially-insured COPD patients, although Dalal et al reported an observational study comparing economic outcomes for FSC, ipratropium, and tiotropium in a Medicare-eligible population. ${ }^{8}$ The purpose of this study was to describe and compare the health care utilization and cost outcomes in a patient population aged 40 years and older receiving FSC, a short-acting anticholinergic, or a long-acting anticholinergic as initial maintenance therapy for COPD.

\section{Methods}

In this retrospective, observational cohort study, clinical and economic COPD-related outcomes were evaluated in patients with COPD who received one of three medications for initial maintenance therapy for COPD, ie, FSC $250 \mu \mathrm{g} / 50 \mu \mathrm{g}$, ipratropium alone or in fixed dose combination with albuterol (hereafter referred to as “ipratropium”), or tiotropium.

\section{Data source}

Administrative data for January 1, 2002 through June 30, 2009 were obtained from the IMS LifeLink Health Plan Claims Database (IMS Health, Watertown, WA), which contains enrollment and demographic data, health care facility and professional services claims ("medical" claims), and outpatient pharmacy claims from more than 70 US health plans covering more than 40 million patients. The dataset had been deidentified in compliance with the patient privacy regulations of the US Health Insurance Portability and Accountability Act. Facility claims in the LifeLink database include date of service, service location, and International Classification of Diseases, 9th Edition, Clinical Modification (ICD-9-CM) diagnosis and procedure codes. Professional service claims include date of service, service location, and Current Procedural Terminology, Version 4 (CPT-4) procedure codes. Pharmacy claims include the National Drug Code and dispensing date; in addition, quantity and number of therapy days dispensed are provided by most health plans in the database. Most health care claims include billed charges; charges are imputed for claims with missing charges due to capitation arrangements. Enrollment, demographic, medical claims, and pharmacy claims for a given individual are linked using a unique encrypted identifier.

\section{Study sample}

The study sample comprised patients who were naïve to maintenance treatment. Potentially eligible patients were enrolled in a health plan between January 1, 2004 and June 30, 2009, and had an initial pharmacy claim for one of the maintenance therapies (FSC, ipratropium, or tiotropium) between July 1, 2004 and March 30, 2009. The initial claim date was designated the index date. Eligible patients also met the following criteria: age 40 years or older on the index date; had a primary or secondary diagnosis of COPD (ie, at least one emergency department visit, one hospitalization, or two outpatient visits with a primary or secondary ICD-9-CM code of 491.xx, 492.xx, or 496.xx during the baseline period); had at least one pharmacy claim for an initial maintenance therapy medication (including the index claim) in the follow-up period; had at least six months of continuous enrollment prior to the index date (the "baseline period"); and had 3-12 months of continuous enrollment after the index date (the "follow-up period") to be eligible for the "risk population" analysis and had at least 12 months of continuous enrollment after the index date to be eligible for the utilization and cost population ("cost population") analysis.

Patients were excluded if they had: a pharmacy fill for a study medication (FSC, ipratropium, or tiotropium), budesonide/formoterol, ICS alone, or LABA alone during the baseline period; a pharmacy fill for an alternate initial maintenance therapy medication within 60 days of the index date; or a primary or secondary diagnosis of respiratory tract 
cancer (larynx, trachea, or pleura; ICD-9-CM codes 161, 161.X, 162, 163, 163.X, 231, 231.X) during the baseline period. To remove outliers, patients were excluded if there was evidence they had more than 30 fills for the initial maintenance therapy medication in a 12-month postindex period or if the cost per 30-day fill of the initial maintenance therapy medication was more than five times the interquartile range above the 75 th percentile (a variation on the Tukey outlier test of 1.5 times the interquartile range). ${ }^{14}$

\section{Analysis}

Demographic information and utilization records in the baseline period were used to characterize the cohorts, and utilization records in the follow-up period were used to evaluate outcomes.

The measured outcome in the risk population analysis was the time-to-first health care event following initiation of maintenance therapy. Health care events evaluated were COPD-related outpatient visits with an antibiotic or oral corticosteroid prescription within 10 days of the visit, emergency department visit, hospitalization, and emergency department visit/hospitalization (combined endpoint). Outcomes evaluated in the cost population analysis were mean health care utilization, unadjusted costs, and adjusted costs. The categories of health care utilization were COPD-related outpatient visits, emergency department visits, hospitalizations, and outpatient pharmacy. In addition, we examined a combined endpoint of hospitalization/emergency department visit, and for COPD-related outpatient visits we separately examined visits associated with a prescription fill for an oral corticosteroid or antibiotic within 10 days of the visit. The categories of costs analyzed in the cost population were medical costs, pharmacy costs, and total costs. In the analyses of both the cost and risk populations, an emergency department visit that resulted in an inpatient admission was not counted in the emergency department visit category in order to avoid double counting of episodes of care. However, the costs of these inpatient-linked emergency department visits were included when calculating total admission costs in order to avoid underestimation of health care costs.

Cox proportional hazard models were used to assess the risk of COPD exacerbations in the FSC, ipratropium, and tiotropium cohorts of the risk population. Kaplan-Meier survival curves for time-to-first-hospitalization/emergency department visit/outpatient visit (combined endpoint) were also modeled. Outcomes were assessed with follow-up starting 30 days postindex date to ensure patients were allowed adequate exposure to the study medication before attributable outcomes were assessed. Patients lost to follow-up were censored. The models adjusted for age, gender, geographic region, baseline comorbidities, and utilization; factors significant at $P \leq 0.20$ and affecting more than $2 \%$ of any cohort or deemed clinically meaningful were included as covariates. Appropriate model fit statistics and assumptions were evaluated and assessed. Sensitivity analyses were conducted (results not shown) in which the outcomes were assessed beginning day 1 postindex date, and, in addition to censoring patients lost to follow-up, patients who filled a prescription for an alternative initial maintenance therapy medication prior to the health care event or who filled a prescription for budesonide/ formoterol, ICS alone, LABA alone, leukotriene modifier, or methylxanthine prior to the event were censored.

For the cost population, the mean number of COPD-related health care utilization events, mean unadjusted costs, and mean adjusted costs were calculated. Costs were inflated to 2009 dollars on a monthly basis using the medical care portion of the consumer price index. Generalized linear models with a log-link and gamma family distribution were used to estimate predicted (adjusted) annual costs. The model controlled for differences between the cohorts in age, gender, treatment, comorbidities, and COPD-related health care utilization at baseline. Both absolute adjusted costs and cost differences are reported. The reported absolute adjusted costs are predicted values from the gamma regression models, with significance for mean differences calculated using Wald Chi-square test. Bootstrapping using the percentile method with 1000 sample simulations was used to estimate $95 \%$ confidence intervals (CI) for mean adjusted cost differences.

Demographic and other baseline characteristics of the cohorts are described as counts and percentages for categorical variables and measures of central tendency (mean or median and standard deviation [SD]) for continuous variables. $P$ values were calculated using the Chi-square test for frequencies and $t$-test for continuous variables; the Wilcoxon rank sum test was used for differences in costs. Statistical tests were two-sided, with an $\alpha$-level of 0.05 for statistical significance. All analyses were conducted using SAS version 9.1.3 or 9.2 for Windows (SAS Institute, Cary, NC).

\section{Results}

\section{Risk analysis}

A total of 43,792 subjects met the inclusion criteria for the risk population; 16,684 in the FSC cohort, 14,449 in the ipratropium cohort, and 12,659 in the tiotropium cohort (Figure 1). Mean age of the cohorts at baseline ranged from 62.8 to 65.2 years (Table 1 ). Selected comorbidities are 


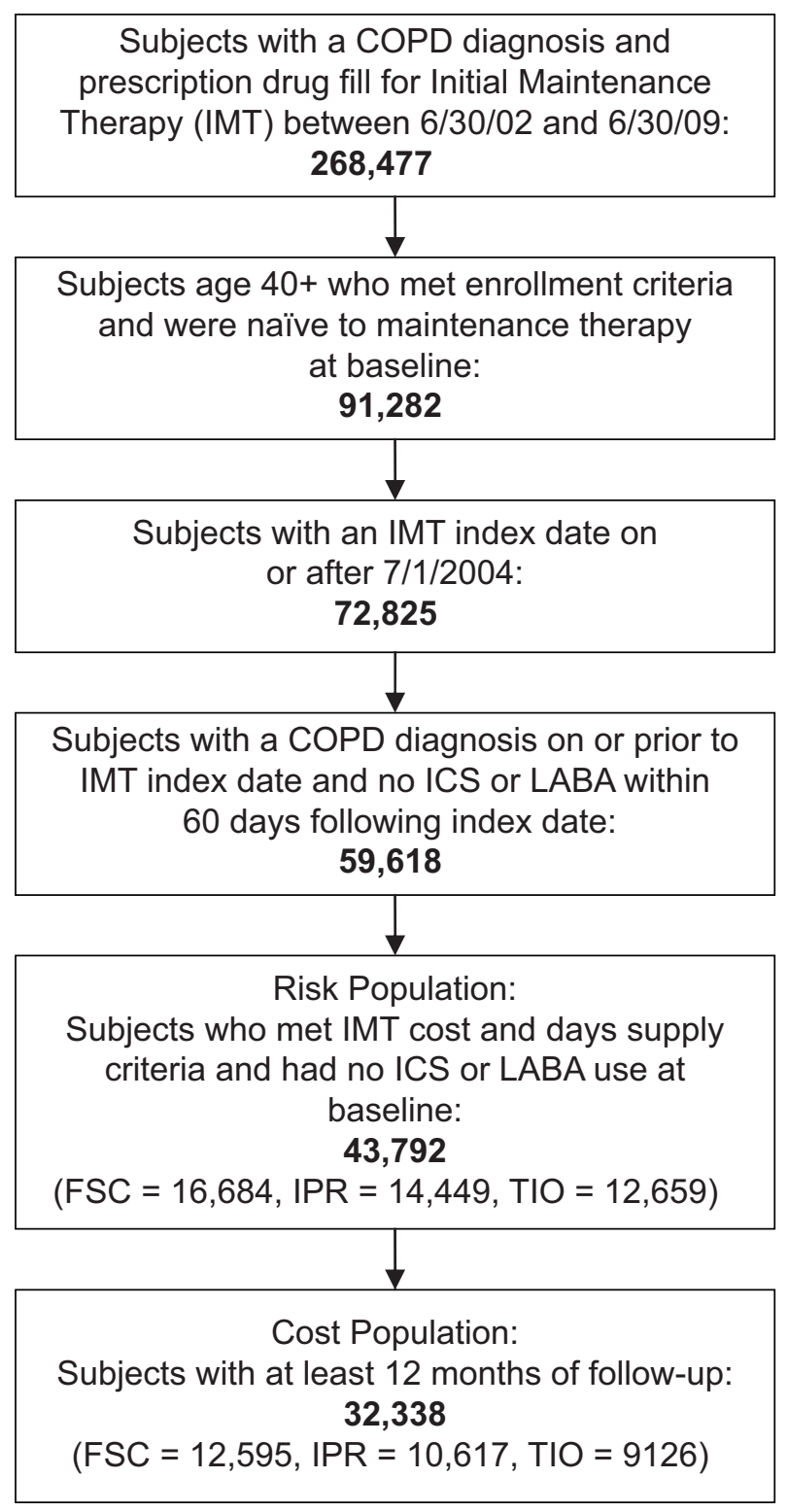

Figure I Patient selection.

shown in Table 1. The FSC cohort had a higher prevalence of asthma than the other two groups, the ipratropium cohort had a higher prevalence of depression than the FSC cohort, and both the ipratropium and tiotropium cohorts had a higher prevalence of congestive heart failure and hypertension than the FSC cohort (all $P<0.05$ ). The FSC cohort also had the highest percentage of patients with a claim for a short-acting beta-agonist at baseline $(25.0 \%$ for FSC versus $14.1 \%$ for ipratropium and $20.3 \%$ for tiotropium; both $P<0.05)$.

Using the FSC cohort as the reference, both the ipratropium and tiotropium cohorts had significantly higher time-to-first event hazard ratios (HRs) for health care utilization events (Table 2). In the ipratropium cohort, the HRs ranged from 1.39 for an outpatient visit with antibiotic to 1.78 for an emergency department visit. The increased risks for tiotropium were slightly lower, ranging from 1.29 for a hospitalization and/or emergency department visit (combined endpoint) to 1.49 for an outpatient visit with oral corticosteroids. In the sensitivity analyses that were conducted using a different follow-up start date (ie, beginning day 1 rather than day 30 after the index date) or different patient censoring criteria, significantly higher risks remained for the ipratropium and tiotropium cohorts compared with the FSC cohort for all four utilization events. The Kaplan-Meier survival curves for any COPD-related health care utilization event are shown in Figure 2. The curves further illustrate that, on average, the ipratropium and tiotropium groups, in comparison with the FSC group, had shorter times between initiation of therapy and the occurrence of a COPD-related health care event.

\section{Cost and utilization analysis}

A total of 32,338 patients met the inclusion criteria for the cost population, comprising 12,595 in the FSC cohort, 10,617 in the ipratropium cohort, and 9126 in the tiotropium cohort (Figure 1). The demographic, clinical, and other baseline characteristics of this cost population (data not shown) are similar to those of the risk population.

A total of $8.9 \%$ of patients had either a COPD-related emergency department visit or hospitalization and 34.2\% had a COPD-related outpatient visit in the follow-up period; $2.7 \%$ had an outpatient visit with oral corticosteroids and $4.9 \%$ had an outpatient visit with antibiotics. Mean health care utilization during the follow-up period, including the mean medication possession ratio for each cohort's initial maintenance therapy medication, is shown in Table 3. The medication possession ratio represents the number of therapy days covered by the dispensed medication fills divided by the days in the observation period. No cohorts had a mean medication possession ratio above $50 \%$ for the COPD maintenance medication. The medication possession ratios were lowest for the ipratropium cohort (22\%) and highest for the tiotropium cohort $(41 \%)$. To ensure that the index pharmacy claim represented maintenance therapy initiation rather than a therapy switch, patients in this study could not have a prescription claim for an alternate initial maintenance therapy medication within 60 days of initial maintenance therapy initiation. After the 60 -day period, approximately $13 \%$ of patients in each cohort had pharmacy claims for an alternate maintenance therapy (patients were followed within their assigned cohort regardless of changes in regimen after 60 days, in concordance with 
Table I Demographic and clinical characteristics of study population ("risk population")

\begin{tabular}{|c|c|c|c|}
\hline & $\begin{array}{l}\text { FSC } \\
(n=16,684)^{a}\end{array}$ & $\begin{array}{l}\text { Ipratropium } \\
(n=14,449)^{a}\end{array}$ & $\begin{array}{l}\text { Tiotropium } \\
(\mathrm{n}=12,659)^{\mathrm{a}}\end{array}$ \\
\hline Age, mean (SD) & $62.8(12.0)$ & $65.2(12.6)^{b}$ & $64.5(11.3)^{b}$ \\
\hline Female & $9127(54.7)$ & $7143(49.4)^{b}$ & $5862(46.3)^{\mathrm{b}}$ \\
\hline$\geq 12$ months follow-up & I2,595 (75.5) & $10,617(73.5)^{b}$ & $9126(72.1)^{b}$ \\
\hline \multicolumn{4}{|l|}{ Selected comorbid conditions: } \\
\hline Asthma & $4077(24.4)$ & $195 \mid(13.5)^{\mathrm{b}}$ & $1510(11.9)^{\mathrm{b}}$ \\
\hline Congestive heart failure & $1850(\mid 1.1)$ & $2967(20.5)^{\mathrm{b}}$ & $1945(15.4)^{\mathrm{b}}$ \\
\hline Depression & $1153(6.9)$ & $1184(8.2)^{b}$ & $848(6.7)$ \\
\hline Hypertension (uncomplicated) & $8098(48.5)$ & $7627(52.8)^{\mathrm{b}}$ & $6484(51.2)^{\mathrm{b}}$ \\
\hline \multicolumn{4}{|l|}{ COPD-related utilization in preindex period: } \\
\hline Outpatient visit & $5173(31.0)$ & $4426(30.6)$ & $540 \mathrm{I}(42.7)^{\mathrm{b}}$ \\
\hline Outpatient visit with oral corticosteroid & $509(3.1)$ & $669(4.6)^{b}$ & $353(2.8)$ \\
\hline Outpatient visit with antibiotic & $865(5.2)$ & $1030(7.1)^{\mathrm{b}}$ & $692(5.5)$ \\
\hline Emergency department visit & $408(2.4)$ & $609(4.2)$ & $336(2.7)$ \\
\hline Hospitalization & $811(4.9)$ & $1428(9.9)^{\mathrm{b}}$ & $895(7.1)^{b}$ \\
\hline Emergency department visit or hospitalization & $1184(7.1)$ & $1983(13.7)^{\mathrm{b}}$ & $1184(9.4)^{b}$ \\
\hline Short-acting $\beta$-agonist & $4178(25.0)$ & $2044(14.1)^{b}$ & $2572(20.3)^{\mathrm{b}}$ \\
\hline \multicolumn{4}{|l|}{ Health care costs in preindex period, mean (SD): } \\
\hline Medical & $993(16,589)$ & $2162(12,722)^{b}$ & $1459(12,439)^{b}$ \\
\hline Pharmacy & $49(165)$ & $32(135)^{b}$ & $33(106)^{b}$ \\
\hline Total & $1042(16,589)$ & $2193(12,721)^{b}$ & $1492(12,439)^{b}$ \\
\hline
\end{tabular}

Notes: ${ }^{a} \mathrm{All}$ figures are $\mathrm{n}(\%)$ unless otherwise noted; ${ }^{\mathrm{b}}<0.05$ for difference with FSC cohort.

Abbreviations: COPD, chronic obstructive pulmonary disease; FSC, fluticasone propionate/salmeterol combination.

an intent-to-treat approach). COPD-related hospitalizations, emergency department visits, and outpatient visits associated with an antibiotic or oral corticosteroid prescription medication fill can be considered as a reasonable proxy measure of COPD exacerbations. These encounters consistently occurred more often in the ipratropium and tiotropium cohorts than in the FSC cohort (all $P<0.05$ ). Unadjusted mean costs are also shown in Table 3; total COPD-related costs for the FSC

Table 2 Results from Cox proportional hazard analyses examining risk of COPD exacerbations between study cohorts ("risk population")

\begin{tabular}{|c|c|c|}
\hline \multirow[t]{2}{*}{$\begin{array}{l}\text { COPD-related } \\
\text { utilization }\end{array}$} & $\begin{array}{l}\text { Ipratropium } \\
n=14,449\end{array}$ & $\begin{array}{l}\text { Tiotropium }^{a} \\
n=12,659\end{array}$ \\
\hline & \multicolumn{2}{|c|}{$\begin{array}{l}\text { Hazard ratio ( } 95 \% \text { confidence } \\
\text { interval) })^{b, c}\end{array}$} \\
\hline $\begin{array}{l}\text { Outpatient visit with } \\
\text { oral corticosteroid }\end{array}$ & $1.65(1.4 \mid-1.94)$ & $1.49(1.26-1.76)$ \\
\hline $\begin{array}{l}\text { Outpatient visit with } \\
\text { antibiotic }\end{array}$ & $1.39(1.23-1.57)$ & $1.33(1.17-1.51)$ \\
\hline $\begin{array}{l}\text { Emergency department } \\
\text { visit }\end{array}$ & $1.78(1.59-2.00)$ & $1.33(1.17-1.5 \mathrm{I})$ \\
\hline $\begin{array}{l}\text { Hospitalization or emergency } \\
\text { department visit }\end{array}$ & I.64 (I.50-I.79) & $1.29(1.17-1.41)$ \\
\hline
\end{tabular}

Notes: a With reference to the FSC cohort; ${ }^{\mathrm{b}}$ The postindex date period ranged from 3 to 12 months; follow-up began on day 30 following initiation of initial maintenance therapy; 'Adjusted for age, gender, treatment, and comorbidities and COPD-related health care utilization at baseline.

Abbreviations: COPD, chronic obstructive pulmonary disease; FSC, fluticasone propionate/salmeterol combination. cohort (\$2018) were lower than for the ipratropium (\$2809) and tiotropium $(\$ 2453)$ cohorts.

Mean adjusted 12-month COPD-related total health care costs also were lower for FSC compared with ipratropium or tiotropium (both differences $P<0.05$ ) (Figure 3 ). The differences in mean adjusted costs are shown in Table 4; compared with FSC, total costs were $\$ 773$ higher for ipratropium and \$339 higher for tiotropium.

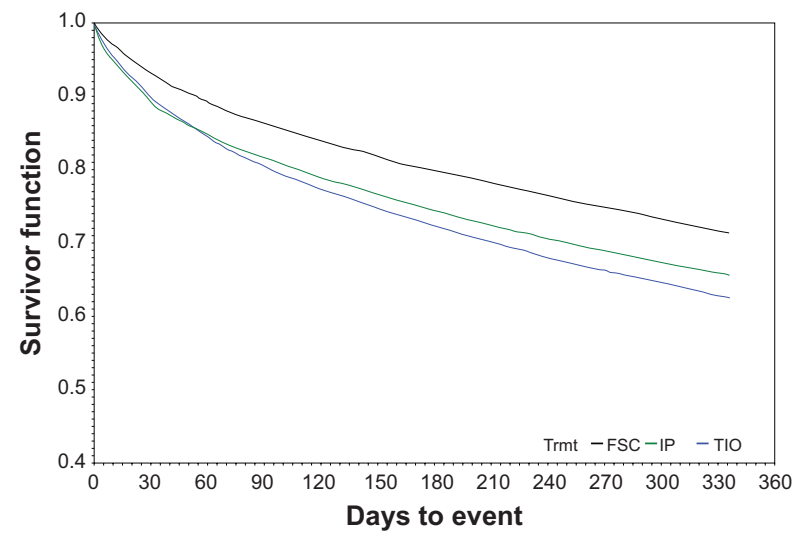

Figure 2 Time to any event ${ }^{\mathrm{a}}$ Kaplan-Meier survival curve: Initial maintenance therapy with FSC, tiotropium, or ipratropium. ${ }^{\mathrm{b}, \mathrm{c}}$

Notes: any COPD-related outpatient visit, emergency department visit or inpatient admission; 'Follow-up period ranged from 3 to 12 months; 'For determining the survival function, follow-up began on day 30 following initiation of initial maintenance therapy.

Abbreviation: COPD, chronic obstructive pulmonary disease; FSC, fluticasone propionate/salmeterol combination. 
Table 3 Unadjusted COPD-related health care utilization and costs associated with initial maintenance therapies in the one-year follow-up period (“cost population")

\begin{tabular}{|c|c|c|c|c|c|}
\hline & $\begin{array}{l}\text { FSC } \\
(n=12,595)\end{array}$ & $\begin{array}{l}\text { Ipratropium } \\
(n=10,617)\end{array}$ & $P$ value ${ }^{a}$ & $\begin{array}{l}\text { Tiotropium } \\
(n=9 \mid 26)\end{array}$ & $P$ value $^{\mathrm{a}}$ \\
\hline \multicolumn{6}{|l|}{ COPD medication utilization } \\
\hline \multicolumn{6}{|l|}{$\begin{array}{l}\text { primary initial maintenance } \\
\text { therapy medication (mean, SD) }\end{array}$} \\
\hline \multicolumn{6}{|l|}{ Alternate maintenance therapy, $\mathrm{n}(\%)$} \\
\hline FSC & na & $795(7.5)$ & - & $839(9.2)$ & - \\
\hline Ipratropium & $7 \mid 3(5.7)$ & na & - & $46 I(5.1)$ & $<0.001$ \\
\hline Tiotropium & $956(7.6)$ & $790(7.4)$ & $<0.876$ & na & - \\
\hline Any alternate maintenance therapy & I57| (I2.5) & $1367(12.9)$ & 0.560 & I208 (I3.2) & 0.187 \\
\hline SABA prescription fills, mean (SD) & $1.44(2.90)$ & $0.81(2.45)$ & $<0.001$ & $1.48(3.13)$ & 0.4029 \\
\hline \multicolumn{6}{|c|}{ COPD-related health care utilization, $\mathbf{n}(\%)$} \\
\hline Hospitalization & $446(3.5)$ & $65 I(6.1)$ & $<0.001$ & $413(4.5)$ & $<0.001$ \\
\hline Outpatient visit w/oral corticosteroid & $26 I(2.1)$ & $354(3.3)$ & $<0.001$ & $262(2.9)$ & $<0.001$ \\
\hline Outpatient visit with antibiotic & $490(3.9)$ & $617(5.8)$ & $<0.001$ & $478(5.2)$ & $<0.001$ \\
\hline Emergency department visit & $450(3.6)$ & $778(7.3)$ & $<0.001$ & $427(4.7)$ & $<0.001$ \\
\hline Outpatient visit & $3615(28.7)$ & $3788(35.7)$ & $<0.001$ & $366 \mathrm{I}(40.1)$ & $<0.001$ \\
\hline Hospitalization/emergency department visit & $819(6.5)$ & $1284(12.1)$ & $<0.001$ & $764(8.4)$ & $<0.001$ \\
\hline \multicolumn{6}{|c|}{ COPD-related health care utilization, mean (SD) } \\
\hline Outpatient visit & $0.76(2.24)$ & $1.28(3.13)$ & $<0.001$ & $1.26(3.14)$ & $<0.001$ \\
\hline Outpatient visit with oral corticosteroid & $0.03(0.27)$ & $0.05(0.33)$ & $<0.001$ & $0.04(0.28)$ & 0.0153 \\
\hline Outpatient visit with antibiotic & $0.05(0.32)$ & $0.08(0.40)$ & $<0.001$ & $0.07(0.37)$ & $<0.001$ \\
\hline Emergency department visit & $0.04(0.28)$ & $0.09(0.37)$ & $<0.001$ & $0.06(0.28)$ & 0.0044 \\
\hline Hospitalization & $0.04(0.24)$ & $0.08(0.34)$ & $<0.001$ & $0.06(0.29)$ & 0.0011 \\
\hline Hospitalization/emergency department visit & $0.09(0.40)$ & $0.17(0.55)$ & $<0.001$ & $0.11(0.44)$ & $<0.001$ \\
\hline \multicolumn{6}{|c|}{ COPD-related health care costs, mean (SD) } \\
\hline Medical $^{b}$ & $\$ 1058(\$ 7545)$ & $\$ 2179(\$ 12,094)$ & $<0.001$ & $\$ 1485(\$ 9489)$ & 0.001 \\
\hline Pharmacy ${ }^{c}$ & $\$ 960(\$ 1040)$ & $\$ 630(\$ 945)$ & $<0.001$ & $\$ 968(\$ 949)$ & 0.551 \\
\hline Total & $\$ 2018(\$ 7658)$ & $\$ 2809(\$ 12,219)$ & $<0.001$ & $\$ 2453(\$ 9588)$ & 0.001 \\
\hline
\end{tabular}

Notes: ${ }^{a}$ For difference with FSC cohort; ${ }^{b}$ Medical costs include outpatient, emergency department, and inpatient care; 'Pharmacy costs include all outpatient prescription medication costs (includes cost of study medication as well as other COPD medications dispensed after the 60-day postindex date window).

Abbreviations: FSC, fluticasone propionate/salmeterol combination; na, not applicable; SABA, short-acting beta-agonist; SD, standard deviation; COPD, chronic obstructive pulmonary disease.

\section{Discussion}

Previous studies have examined outcomes and costs associated with FSC, ipratropium, or tiotropium in different patient populations, but this is the first study to compare all three maintenance therapies in a commercially-insured COPD population in a real-world setting. In the absence of head-to-head clinical trials, observational studies can be valuable from the health plan perspective. In this retrospective, observational study of initial maintenance therapy for COPD we used medical and pharmacy claims data for 32,338 patients (the "cost population") and found lower health care utilization rates associated with FSC compared with ipratropium or tiotropium. In accord with the generally lower utilization rates, COPD-related health care costs also were lower for FSC than for ipratropium and tiotropium, both total costs and component costs, with higher pharmacy costs of FSC therapy more than offset by lower medical costs. Additionally, a time-to-event proportional hazard analysis of 43,792 patients (the "risk population") indicated that those receiving ipratropium or tiotropium for initial maintenance therapy had a higher risk for earlier occurrence of exacerbations as indicated by COPD-related health care events. Compared with FSC, use of tiotropium was associated with a $49 \%$ higher risk for outpatient visit with an oral corticosteroid prescription medication fill, a 33\% higher risk for outpatient visit with an antibiotic fill, a 33\% higher risk for emergency department visit, and a $29 \%$ higher risk for a COPD-related hospitalization/emergency department visit combined endpoint. Adherence to therapy was not high in any of the cohorts, and was similar to values reported in previous studies. ${ }^{5,9}$ During the study period, FSC patients had enough prescription fills to provide therapy for only 
A

$\square$ FSC $\square$ Tiotropium $\mathbf{a}$ Ipratropium

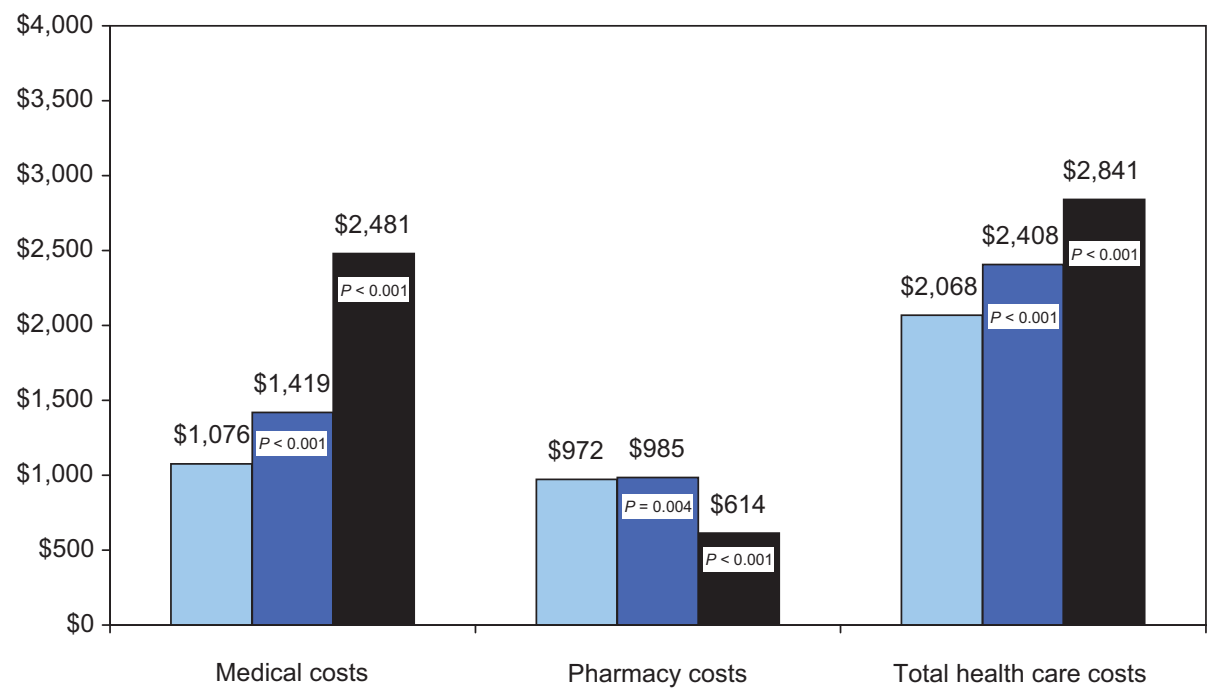

B $\square$ FSC $\square$ Tiotropium $\mathbf{E}$ Ipratropium

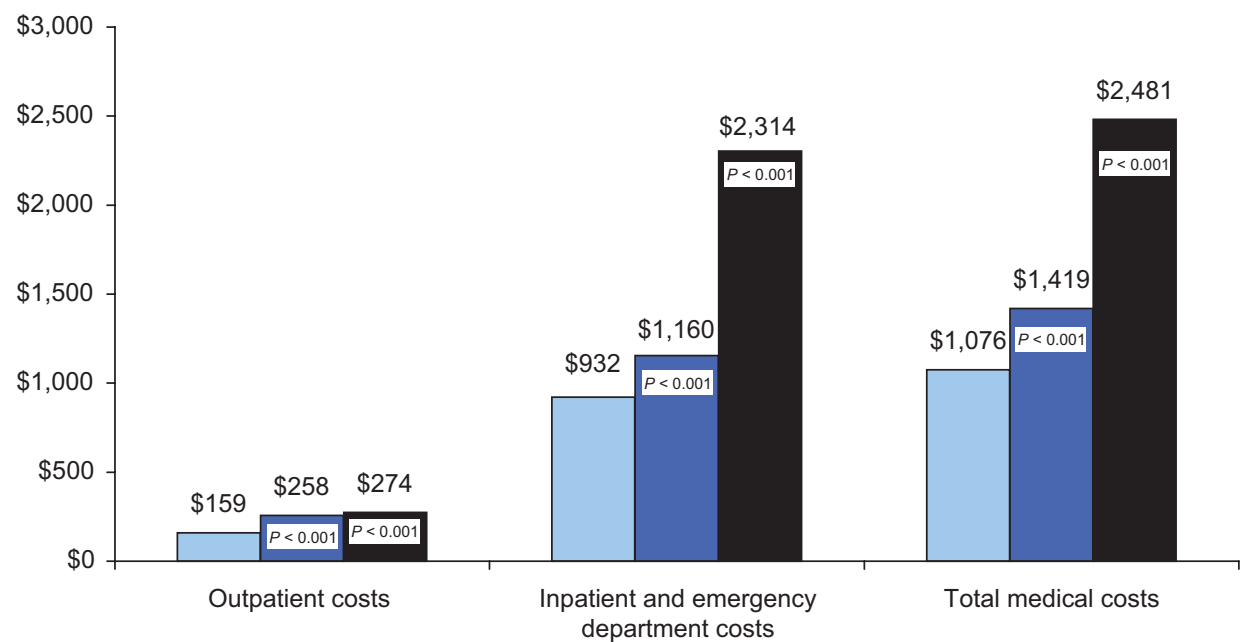

Figure 3 Predicted (adjusted) I2-month COPD-related health care costs (in 2009 \$US) associated with different initial maintenance therapies (data from the "cost population"). A) COPD-related health care costs; B) Breakdown of the medical component of COPD-related health care costs.

Note: a Costs were adjusted for age, gender, treatment, and comorbidities and COPD-related health care utilization at baseline. P-values are for differences between tiotropium and FSC, and between ipratropium and FSC.

Abbreviations: COPD, chronic obstructive pulmonary disease; FSC, fluticasone propionate/salmeterol combination.

$32 \%$ of the 12 -month follow-up period, tiotropium patients had enough for $41 \%$ of the period, and ipratropium patients had enough for just $22 \%$ of the period.

These findings are in general agreement with several prior studies of FSC and ipratropium as maintenance therapy for COPD. ${ }^{5-11}$ Rascati et al found that, compared with ipratropium, combination ICS/LABA therapy was associated with a $27 \%$ reduced risk for any COPD-related event in a cohort of Medicaid enrollees with COPD. ${ }^{11}$ An earlier analysis in a Medicaid population found a 35\% lower risk for COPD-related hospitalization with ICS/LABA compared with ipratropium therapy. ${ }^{10}$ In an evaluation of a higher dosage of FSC (500 $\mu \mathrm{g} / 50 \mu \mathrm{g})$, a $45 \%$ lower risk for a COPD-related hospitalization or emergency department visit with FSC compared with ipratropium was reported for a population aged 65 years and older. ${ }^{7}$ Others have reported a nonsignificant reduction in total health care costs, but a $41 \%$ reduced risk for COPD-related hospitalization or emergency department care with FSC compared with ipratropium. ${ }^{9}$ Additional research has found utilization and cost benefits are associated with tiotropium 
Table 4 Adjusted differences in COPD-related costs in the one-year follow-up period ("cost population")

\begin{tabular}{|c|c|c|}
\hline \multirow[t]{2}{*}{$\begin{array}{l}\text { COPD-related } \\
\text { health care }\end{array}$} & \multicolumn{2}{|c|}{$\begin{array}{l}\text { Difference in adjusted costs relative } \\
\text { to FSC, \$US }(95 \% \mathrm{CI})\end{array}$} \\
\hline & $\begin{array}{l}\text { Ipratropium } \\
(n=10,617)\end{array}$ & $\begin{array}{l}\text { Tiotropium } \\
(\mathrm{n}=9126)\end{array}$ \\
\hline Medical $^{\mathrm{b}}$ & I $405(|329| 490)$, & $344(288,40 I)$ \\
\hline Pharmacy ${ }^{c}$ & $-358(-369,-346)$ & $14(1,26)$ \\
\hline Total $^{\mathrm{d}}$ & $773(7 \mid 6,829)$ & $339(287,395)$ \\
\hline
\end{tabular}

Notes: ${ }^{\text {aC }}$ osts and odds ratios were adjusted for age, gender, treatment and other covariates; 'Medical costs include COPD-related outpatient, emergency department, and inpatient care; ${ }^{\mathrm{C}}$ Pharmacy costs include all outpatient prescription medication costs (includes costs of study medication as well as other COPD medications dispensed after the 60-day postindex date window); ${ }^{\mathrm{d}}$ Costs are not cumulative because individual models were used to predict each component. $\mathrm{Cl}$ were generated by bootstrapping 1000 simulated samples.

Abbreviations: $\mathrm{Cl}$, confidence intervals; COPD, chronic obstructive pulmonary disease; FSC, fluticasone propionate/salmeterol combination.

compared with ipratropium. For example, a cost-effectiveness study of tiotropium versus ipratropium found lower exacerbation rates with tiotropium but an increased incremental cost-effectiveness ratio, ${ }^{12}$ and a randomized clinical trial of tiotropium versus ipratropium found that tiotropium was associated with fewer exacerbations and an increased time to first hospitalization. ${ }^{15}$ In a retrospective, observational study of an older population with COPD, patients aged 65 years and older who received tiotropium as initial maintenance therapy had a 19\% increased risk (HR 1.19) for serious health care events (hospitalization or emergency department visit) in the 12 months following therapy initiation compared with patients who received FSC. ${ }^{16}$ This is lower than the $29 \%$ (HR 1.29) increased risk seen in the somewhat younger population in the present study. In the older population study, mean total costs in the 12 months following therapy initiation were $16 \%$ lower in the FSC group than in the tiotropium group, which is the same percent reduction seen in the present study.

We believe our study is the first to compare FSC, ipratropium, and tiotropium in terms of relative costs, utilization, and time-to-first-event risk in a population of COPD patients aged 40 years and older. Tiotropium and LABA are recommended in clinical guidelines as first-line therapies, with the addition of ICS (or ICS/LABA) recommended for repeated exacerbations. ${ }^{4}$ In this population of maintenance-naïve patients, those receiving ICS/LABA were slightly younger at baseline than the patients receiving either a short-acting or long-acting anticholinergic agent. This study suggests that initial treatment with the ICS/LABA combination, FSC, results in improved costs and outcomes compared with anticholinergic treatment using tiotropium or ipratropium.
This study has several strengths. One is the large sample size, which allowed a robust head-to-head comparison of three maintenance therapies. We ensured that the risk and cost populations studied were naïve to maintenance treatment in order to assess exposure and outcomes adequately. An intent-to-treat approach was used to reflect real-world practice patterns. We required a 60 -day postindex date window during which patients on one study medication could not receive an alternate study medication. This ensured that the treatment a patient was assigned to for analysis purposes did not represent merely a switch in therapy, but was in fact the intended maintenance regimen. After this window, an intent-to-treat approach was employed (ie, patients were followed regardless of adherence or changes in regimen). In the risk analyses, we captured outcomes beginning 30 days after therapy initiation. Immortal time bias, a problem in some survival analyses, does not apply to this analysis, because requirements for cohort entry, drug exposure, and the observable time available between cohort entry and the first outcome event were the same for all cohorts. In addition, to allay concerns about other bias that may have been introduced, we conducted sensitivity analyses in which time-to-event models captured outcomes beginning day 1 following therapy initiation and analyses that incorporated the use of COPD-related medications other than the initial maintenance therapy medication prior to an event. Outcomes in these latter analyses were similar in both magnitude and statistical significance to the primary study model. We also accounted for differences in baseline characteristics between the cohorts by including these characteristics as covariates in multivariable models.

Some limitations of this study should be noted. This was an observational analysis using medical claims data. Because health care claims are limited by a lack of clinical data, COPD severity could not be fully characterized, and some clinical and patient characteristics that might have influenced physicians to provide a particular initial maintenance therapy could not be ascertained. It was observed that a higher percentage of tiotropium patients in the baseline period had a primary, rather than secondary, diagnosis of COPD (as indicated by diagnosis codes in claims data) compared with FSC and ipratropium patients, possibly indicating these patients had more severe, symptomatic, or otherwise more clinically recognizable disease. Although our model controlled for these baseline differences, some residual confounding may be present. It is also possible that physicians are less likely to prescribe FSC than ipratropium 
or tiotropium for patients with relatively more comorbidities; our data show that the FSC cohort had a somewhat lower mean prevalence of several comorbidities than the ipratropium and tiotropium cohorts. Thus, it is possible that the utilization and cost differences seen are due to underlying differences in the health status of the cohorts rather than to the therapeutic agent. In addition, some confounding may have occurred with respect to the particular initial maintenance therapy medication a patient received. While patients were not allowed to have a prescription fill for an alternative initial maintenance therapy medication within the first 60 days following initiation of therapy, they could have such a fill thereafter, and approximately $13 \%$ of each group did fill a prescription for an alternate initial maintenance therapy medication. However, because this crossover was similar in all three groups, any potential bias from crossover is likely to be minimal. Prior research has found that $95 \%$ of COPD cases identified from claims data are confirmed by information contained in the patient's medical record, such as pulmonary function tests, chest x-ray, smoking history, and physical findings. ${ }^{17}$ Nonetheless, the possibility remains that in some cases asthma may have been misclassified as COPD (and vice versa) at the clinic level and the inaccuracy carried over into claims data. Finally, as noted earlier, the benefits of ICS/LABA combination therapy have been demonstrated in several studies, but recent studies have also investigated the efficacy of combining tiotropium and ICS/LABA therapy (triple therapy) in patients with severe COPD. ${ }^{18}$ Although triple therapy may provide additional benefits, investigation of this form of combination treatment for severe COPD was beyond the scope of our study.

To our knowledge, the present study is the first to compare health care utilization and costs between these three maintenance therapies for COPD in a commercially-insured patient population. We found that adjusted COPD-related utilization and costs were lower with FSC than with either ipratropium or tiotropium. In addition, time-to-first-event risks were improved with FSC compared with other maintenance therapies. These findings suggest that initial maintenance therapy with FSC may offer clinical and cost benefit in comparison with short- and long-acting anticholinergics. Considering that the primary goal of COPD management is the prevention and reduction of exacerbations and that this study shows that patients receiving FSC had lower risk for COPD exacerbations, maintenance treatment with FSC may offer some clinical benefits.

\section{Acknowledgment}

The authors thank Judith Hurley for her medical writing services; compensation for these services was provided by GSK.

\section{Disclosure}

AAD is an employee of GlaxoSmithKline (GSK) and owns company stock. CMB, HVP, and MHR are employees of the Lovelace Respiratory Research Institute, which has received research funding from GSK. DWM has received research funding from and served as a consultant to GSK, Pfizer, and Boehringer-Ingelheim. Financial support for this study was provided by GlaxoSmithKline (ADC112646).

\section{References}

1. American Lung Association. Chronic Obstructive Pulmonary disease (COPD) Fact Sheet. Washington, DC: American Lung Association, 2009. Available at: www.lungusa.org/lung-disease/ copd/resources/facts-figures/COPD-Fact-Sheet.html\#note_08. Accessed 2010 Nov 12.

2. National Heart, Lung and Blood Institute. Morbidity and Mortality: 2007 Chartbook on Cardiovascular, Lung, and Blood Diseases. Bethesda, MD: U.S. Department of Health and Human Services; 2007.

3. Celli BR, MacNee W. ATS/ERS Task Force. Standards for the diagnosis and treatment of patients with COPD: A summary of the ATS/ERS position paper. Eur Respir J. 2004;23:932-946.

4. Global Initiative for Chronic Obstructive Lung Disease. Global strategy for diagnosis, management and prevention of COPD. Gig Harbor, WA: Medical Communications Resources, Inc; 2009 Dec.

5. Akazawa M, Hayflinger DC, Stanford RH, Blanchette CM. Economic assessment of initial maintenance therapy for chronic obstructive pulmonary disease. Am J Manag Care. 2008;14:438-448.

6. Anzueto A, McLaughlin T, Stanford RH. Initial treatment regimen and risk of hospitalization in patients with chronic obstructive pulmonary disease. COPD. 2004;1:205-214.

7. Blanchette CM, Akazawa M, Dalal A, Simoni-Wastila L. Risk of hospitalizations/emergency department visits and treatment costs associated with initial maintenance therapy using fluticasone propionate $500 \mu \mathrm{g} / \mathrm{salmeterol} 50 \mu \mathrm{g}$ compared with ipratropium for chronic obstructive pulmonary disease in older adults. Am J Geriatr Pharmacother. 2008;6:138-146.

8. Dalal AA, Petersen H, Simoni-Wastila L, Blanchette CM. Healthcare costs associated with initial maintenance therapy with fluticasone propionate $250 \mu \mathrm{g} / \mathrm{salmeterol} 50 \mu \mathrm{g}$ combination versus anticholinergic bronchodilators in elderly US Medicare-eligible beneficiaries with COPD. J Med Econ. 2009;12:339-347.

9. Delea TE, Hagiwara M, Dalal AA, Stanford RH, Blanchette CM Healthcare use and costs in patients with chronic bronchitis initiating maintenance therapy with fluticasone/salmeterol vs other inhaled maintenance therapies. Curr Med Res Opin. 2009;25:1-13.

10. Rascati KL, Stanford RH, Borker R. A comparison of the risk of hospitalizations due to chronic obstructive pulmonary disease in Medicaid patients with various medication regimens, including ipratropium, inhaled corticosteroids, salmeterol, or their combination. Clin Ther. 2005;27:346-354.

11. Rascati KL, Akazawa M, Johnsrud M, Stanford RH, Blanchette CM. Comparison of hospitalizations, emergency department visits, and costs in a historical cohort of Texas Medicaid patients with chronic obstructive pulmonary disease, by initial medication regimen. Clin Ther. 2007;29:1203-1213. 
12. Oostenbrink JB, Rutten-van Mölken MP, Al MJ, van Noord JA, Vincken W. One-year cost-effectiveness of tiotropium versus ipratropium to treat chronic obstructive pulmonary disease. Eur Respir J. 2004;23:241-249.

13. Wedzicha JA, Calverley PMA, Seemungal TA, et al. The prevention of chronic obstructive pulmonary disease exacerbations by salmeterol/ fluticasone propionate or tiotropium bromide. Am J Respir Crit Care Med. 2008;177:19-26.

14. Tukey JW. Exploratory Data Analysis. 1st ed. Reading, MA: AddisonWesley Publishing Company; 1977.

15. Vincken W, van Noord JA, Greefhorst AP, et al. Improved health outcomes in patients with COPD during 1 year's treatment with tiotropium. Eur Respir J. 2002;19:209-216.
16. Dalal AA, Blanchette CM, Roberts MH, Petersen HV, Mapel DW. Healthcare utilization and direct medical costs associated with initial maintenance therapy with fluticasone propionate $250 \mu \mathrm{g} / \mathrm{salmeterol}$ $50 \mu \mathrm{g}$ combination versus tiotropium in elderly, Medicare-eligible patients with COPD. J Med Econ. 2010 Sep 20. [Epub ahead of print].

17. Mapel DW, McMillan GP, Frost FJ, et al. Predicting the costs of managing patients with chronic obstructive pulmonary disease. Respir Med. 2005;99:1325-1333.

18. Welte T. Optimising treatment for COPD - new strategies for combination therapy. Int J Clin Pract. 2009;63:1136-1149.

\section{Publish your work in this journal}

The International Journal of COPD is an international, peer-reviewed journal of therapeutics and pharmacology focusing on concise rapid reporting of clinical studies and reviews in COPD. Special focus is given to the pathophysiological processes underlying the disease, intervention programs, patient focused education, and self management protocols.

\section{Dovepress}

This journal is indexed on PubMed Central, MedLine and CAS. The manuscript management system is completely online and includes a very quick and fair peer-review system, which is all easy to use. Visit http://www.dovepress.com/testimonials.php to read real quotes from published authors.

Submit your manuscript here: http://www.dovepress.com/international-journal-of-copd-journal 